\title{
A Review on Development of Kek Lapis Sarawak's Machine
}

\author{
Mohamad Syamim Hamsawi ${ }^{1}$, Ana Sakura Zainal Abidin ${ }^{1, ~}{ }^{*}$, Shahrol Mohamaddan ${ }^{1}$, Rasli Muslimen ${ }^{1}$, Mohd Syahmi \\ Jamaludin', Nurul 'Izzati Hashim², Nazreen Junaidi' \\ ${ }^{1}$ Department of Mechanical and Manufacturing Engineering, Faculty of Engineering, Universiti Malaysia Sarawak (UNIMAS), Malaysia \\ ${ }^{2}$ Department of Electrical and Electronic Engineering, Faculty of Engineering, Universiti Malaysia Sarawak (UNIMAS), Malaysia
}

\begin{abstract}
Kek Lapis Sarawak is a beautifully decorated and flavorful cake that can be considered as the artwork of the Malays in Sarawak. There is an overwhelming demand of the Kek Lapis Sarawak in the market that consequently need for automation. This paper summarizes comprehensive reviewed patents of the current machine and journals which have similar functions and related to the current function of manual process of producing Kek Lapis Sarawak. Conceptual idea of the Kek Lapis Sarawak machine consists of three modules namely Depositor Module, Cooling and Pressing Module and Baking Module. Therefore, patents and journals that have similar functions with these modules are reviewed that look into its advantages. The disadvantages of the design also considered for future design. Hence, the crucial advantages of each module considered are namely improved production rates, increased of hygienic rating, easy to maintenance and portability of a design. The reviewed patents and journals can be considered for the development of Kek lapis Sarawak's machine with some improvisations are needed to meet up the specific requirements of the machine.
\end{abstract}

\section{Introduction}

Kek Lapis Sarawak can be considered as the artwork of the Malay people in Sarawak. The uniqueness of the cake's pattern and flavour captures the world's attention. Kek Lapis Sarawak is a must menu during the festive seasons in Sarawak including birthdays and wedding ceremonies. The popularity of the cake creates an overwhelming market demand.

The current production of Kek Lapis Sarawak which is done manually is unable to meet the growing demand. Conventional method involves repetitive processes of depositing, layering, baking, cooling and pressing dependent on number of layered needed [1]. The tedious process is very time consuming and relying on the labour's skills. The issues consequently limit the productivity and quality of the cakes produced. The needs of producing compact and cheaper machine that can produce varieties of Kek Lapis Sarawak caused by the high dependable to a foreign supplier that costs more on the maintenance such as delay in repairing process and international expertise that contributes to the loss of production. Likely, automation of the Kek Lapis Sarawak machine is the most viable solution.

The objective of this paper is to present summary of reviewed any related patent, journal and proceeding that have similar functions to the current process namely

*Corresponding author: zaasakura@unimas.my depositing, baking and layering. Advantages of the reviewed publications can be considered for the development of the future machine. While, any drawback need to be improvised to suite with the specific needs of the Kek Lapis Sarawak machine.

\section{Discussions}

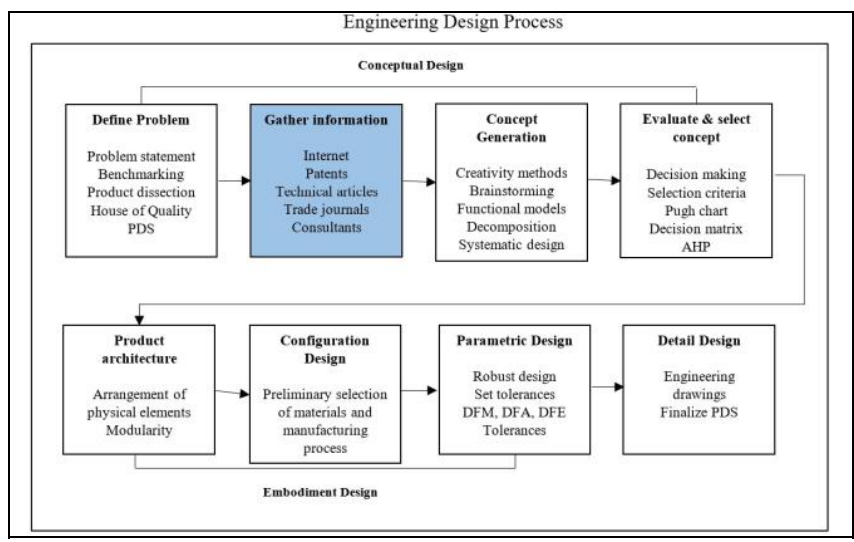

Figure 1. Schematic diagram of Engineering Design Process. [2] 
Currently, this project is in the stage of gather information as illustrated in the higlighted box in Figure 1. Engineering Design Process is one of the method to do the design process [2]. The next stage will be development of conceptual design of the Kek Lapis Sarawak machine.

The conventional method of making Kek Lapis Sarawak can be divided into three main processes namely depositing, cooling and pressing, and baking [1]. The cycle of process Kek Lapis Sarawak production is shown in Figure 2. More over, the number of process cycle is depended on the desired production of the cake. This section presents summary of related publications followed by discussion according to the named processes.

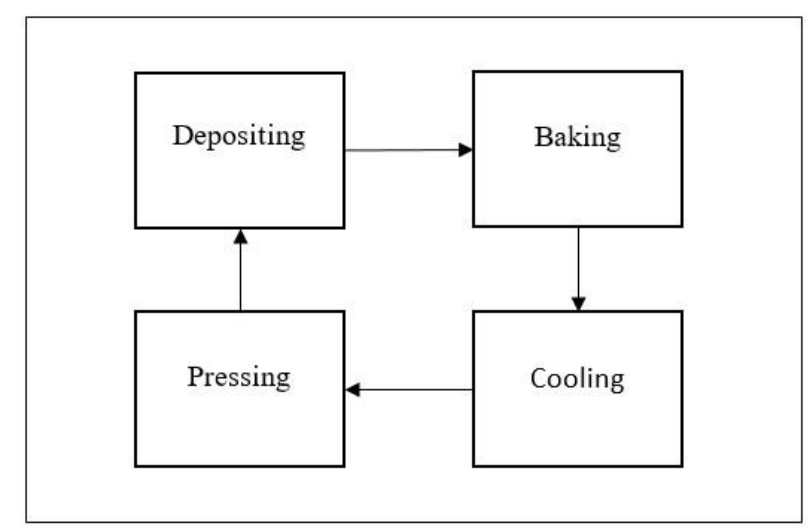

Figure 2. Flow process of cycle of a Kek Lapis Sarawak production. [1]

\subsection{Depositor Module}

Table 1 shows summary of reviewed patents for depositor [3, 11, 16, 20, 22]. "Depositing confectionary nozzle mass" is based on the slit and elongated nozzle mechanism [3-10]. This patent used to deposit chocolate that has quite similar behavior to the cake batter. The negative of de-aeration effect of this patent can be beneficial to the development of Kek Lapis Sarawak's machine because it will improve accuracy of the depositing of the cake batter.

"Volume division dough and implementing device" is based on the hopper design that applies gravitational force [11]. However, this patent claimed that the flow of the dough by gravity is utterly incapable to meet the customary rates of industrial production of bread-making products. Somehow, the idea of using gravitational force is good because it can eliminate additional force needed. Another benefit of this patent is the deformation of the medium that can be controlled. Controlling function is very crucial in the development of Kek Lapis Sarawak as consistency the cake thickness represents the quality of the cake produced [11-15].

"Food flavouring by using a metering roller and a blade" is based on the dispensed by plurality indentations [16]. Those distinctly "chunky" or "gluey" coatings generally tend to obstruct dishing out apparatus and are susceptible to intermittent, irregular flow. The mechanism potentially able to prevent it to occur [16].
Indirectly, the flow of the medium will be in steady flow. This patent can lessen excess of the batter used which can contribute to the optimum production rate [16-19]. Moreover, this patent is easy to maintain which is essential consideration to the development of Kek Lapis Sarawak machine.

"Producing sandwich cookie" having dissimilarly base cakes [20]. This patent is based on hopper filler with nozzle. The medium that has been used in this patent is slightly similar to the medium for Kek Lapis Sarawak's batter which is cream. This patent can controls the flow of the cream through the discharge orifices which it is good for optimum rate of depositing process of the medium. This patent also claimed that it can operates in high speed due to it processing system which is high speed capability [20-21]. This patent also provides continuous production which is good for mass production. Moreover, this patent also equipped changeable molder that make it more portable. Unfortunately, the rotary molder part is not suitable to dispense Newtonian fluid and Non-Newtonian fluid because it is built to deposit dough.

"High viscosity dough depositor machine" is based on hopper and a die concept [22]. It is mentioned that the dough transfer of the die could provide $50 \%$ greater than conventional dies for the identical size baked product which lead to increase the production rate. Moreover, this patent tolerate for enhanced deposit of the high viscosity of non-traditional dough and resolve readily spread to the preferred product form [22]. Besides, it could save time in depositing process and lead to improve the production rate which is essential for development of Kek Lapis Sarawak's machine.

Unfortunately, many of these patents are limited to solid state or dough characteristic $[3,11,16,20,22]$. The idea of the mechanisms are informative for the development of Kek lapis Sarawak's machine but different characteristic of the transported medium for the cake batter as Non-Newtonian fluid must be improvised.

\subsection{Cooling and Pressing Module}

Table 2 shows summary for cooling and pressing mechanism [23, 31, 38, 44]. Most of the available cooling mechanism applied fan structured. Cooling structure of electronic equipment rack is based on the ordinary fan structured [23]. The patent provides constant air speed for steady flow of air ventilation in order to achieve stable cooling effect [24-30]. Moreover, this patent produce less noise due to arrangement of the fan itself that enable the fans to operate with less noise. However, this patent is considered as expensive as more fans needed to provide stable cooling effect. At the same time, the patent has limited degree of freedom because of the arrangement of the fans are placed in vertical upwards.

The next cooling mechanism is vacuum cooling. The mechanism is able to cool down without damaging the cake [31]. This patent is recommended for hygienic and safety. This patent potentially meet the requirement for hygiene and safety criteria of the development of Kek Lapis Sarawak's machine. Moreover, this patent is also 
efficient for product with medium of slurries characteristic which is difficult to cool [32-35]. However, there is drawback of the vacuum cooling mechanism which is high in capital investment. Therefore, the mechanism is recommended for long term operation as upsetting for short term of operation can lead to loss. The mechanism can be considered as the development of the Kek Lapis Sarawak's machine is targeted for mass production.

In spite of that, the process is quite grimy when operated. The sauces splattered on the roofs of processing tunnel during vacuum cooling and strenuous to clean [36]. Moreover, the product aroma is disturbed due to vacuum cooling which might reduce quality of the product [37]. On top of that, if the vacuum cooling process is operate at low vacuum state, the process will not fully satisfied the objective. Thus, the mechanism must be ran at high pressure that consequently consume a lot of power. Therefore, the idea can be considered with some improvements to meet up the requirements needed.

Pressing mechanism has very limited design concepts as most of the pressing part applied in the current designs are stamper and roller presser. "Device for pressing the coffee powder within the filter holder" has applied concept of stamper presser [38]. This patent provides easy to maintenance since is easy to clean after being used. The reliability on the stamper presser is considered as good to the current development of Kek Lapis Sarawak's machine because the patent is able to provide equal pressure to the whole cake surface that potentially able to produce better quality cake that has firm texture [39]. Besides, pressure of the presser can be controlled to any part of the cake surface with specific amount of pressure either little or harder pressure [4043].

"Bun machine" is based on the concept of roller presser [44]. This patent need less maintenance as it is easy to clean due to simple assembly. Moreover, this patent can be considered for the development of Kek Lapis Sarawak's machine because the pressure exert from the presser is able to spread evenly and more reliable [4451]. This patent also consume less space that can be considered for compact design and less material usage.

\subsection{Baking Module}

Table 3 shows summary of reviewed patents for baking module [52, 58, 64, 68, 74]. "Convection oven" using steam as heating element [52]. This patent provides portability in accessible of electrical components which is essential for development Kek Lapis Sarawak's machine [52-57]. Moreover, variable in speed by the reversible blower during operation is one of the important consideration of the develop machine that allows for heat controlling. Thus, it could improve the production rate. Unfortunately, maintenance seems hard for the patent because it is not reliable. Besides, this patent is not ecofriendly because the heat emitted by the gas.

"Conveyor oven" is based on infrared radiation heating for heating element [58]. This patent offers moveable design in which needed for development of
Kek Lapis Sarawak's machine by accessible of changing parts [59]. Thus, make it is easy to maintain [58-63]. Moreover, this patent also provides optimum baking capacity that consequently increase the production rate [58-63]. However, the heat emitted by this patent is not fully utilized because of the open space. Hence, this idea can be considered but need some improvements.

"Forced convection gas oven" is operated by gas [64]. The heat transfer is caused by the burning of the liquefied petroleum gas (LPG). Heat of the oven is fully utilized as the patent applied closed design concept [6467]. However, this patent is not portable. Hence, it is hard to maintain because of inaccessibility of the compact design.

"Multi access microwave oven" applied microwave radiation for its heating element [68]. The emitted microwave radiation improved the efficiency of the cooking method because the radiation is able to cook with less power and faster as multiple unit of microwave ovens can be installed [68-73]. Unfortunately, the price is higher than a conventional microwave oven. Moreover, this patent is hard to maintenance due to its closed design.

"Bidirectional heating cooker" is based on infrared radiation as its heating element [74]. This patent capable in controlling heat emitted by the infrared radiation [74]. Thus, controllable heat transfer could improves the production rate which is good for development of Kek Lapis Sarawak's machine [74-78]. Furthermore, suitable amount of infrared radiation in this patent is able to improve the cooking efficiency [74-78]. Unfortunately, this patent is hard to maintain because of the complexity of the design. 
Table 1. The reviews for Depositor Module.

\begin{tabular}{|c|c|}
\hline Details & Mechanisms \\
\hline $\begin{array}{l}\text { Name: Depositing confectionery mass } \\
\text { (Slit and elongated nozzle). [3] }\end{array}$ & $\begin{array}{l}\text { Depositing confectionery mass comprising at least one discharge passageway extending to at least one elongate discharge } \\
\text { outlet, wherein at least one discharge passageway diverges in a direction towards the discharge outlet, and a machine for } \\
\text { producing a confectionery product having at least one such apparatus for depositing. In a method of producing a confectionery } \\
\text { product, the confectionery mass is deposited as at least one strip having a width in the range of } 5 \text { to } 500 \mathrm{~mm} \text { and/or thickness } \\
\text { in the range of } 0.5 \text { to } 100 \mathrm{~mm} \text {. [3] } \\
\text { * Related mechanism for Slit and elongated nozzle. [4-10] }\end{array}$ \\
\hline $\begin{array}{l}\text { Name: Volume division dough and } \\
\text { implementing device (Hopper). [11] }\end{array}$ & $\begin{array}{l}\text { It concerns a method for volume division of bread-making, bakery, and pastry dough and the like, contained in a hopper. The } \\
\text { method includes allowing the dough to by gravity into a chamber capable of measuring an amount of dough to be divided and } \\
\text { extending beneath an opening located at the base of the hopper. [11] } \\
\text { * Related mechanism Hopper. [12-15] }\end{array}$ \\
\hline $\begin{array}{l}\text { Name: Food flavouring by using a metering } \\
\text { roller and a blade (Dispensed by plurality } \\
\text { indentations). [16] }\end{array}$ & $\begin{array}{l}\text { An exterior axial surface of the metering roller may define a plurality of indentations, which may be configured to capture the } \\
\text { food flavoring as the metering roller rotates. The system may also include a metering blade and a displacement; each may be } \\
\text { coupled to the frame. The metering blade may be configured to level the food flavoring as the food flavoring is dispensed by } \\
\text { the plurality of indentations of the metering roller as the metering roller rotates. The displacement blade may have a plurality } \\
\text { of teeth that are configured to correspond to the plurality of indentations. The teeth may be configured to positively displace } \\
\text { the food flavoring as the metering roller rotates. [16] } \\
\text { * Related mechanism Dispensed by plurality indentations. [17-19] }\end{array}$ \\
\hline $\begin{array}{l}\text { Name: Method for producing sandwich } \\
\text { cookie having dissimilarly-sized base cakes } \\
\text { (Hopper filler and nozzle). [20] }\end{array}$ & $\begin{array}{l}\text { Continuously producing a sandwich cookie having dissimilarly-sized base cakes and for producing filled deep-walled cookies } \\
\text { or cookie cups. The production of the sandwich cookies includes at least one rotary molder for producing lower base cakes } \\
\text { and upper base cakes and a filler cream depositor that deposits a layer of filler cream on each of the lower base cakes. [21] } \\
\text { * Related mechanism for Hopper filler and nozzle. [20-21] }\end{array}$ \\
\hline $\begin{array}{l}\text { Name: High viscosity dough depositor } \\
\text { machine (Hopper and a die). [22] }\end{array}$ & $\begin{array}{l}\text { Hopper receive a supply of dough. A forming portion comprising a die having at least one dough transfer port through which } \\
\text { the dough is extrude-able to form the dough into a predetermined shape, wherein the at least one dough transport comprises a } \\
\text { cross sectional area not less than about } Ґ 0.75 \text { in } \ \wedge 2 \text { and a diameter of at least about } 1 \text { inch. The dough been delivered by the } \\
\text { hopper and being transferred to roller. [22] }\end{array}$ \\
\hline
\end{tabular}

Table 2. The reviews of Cooling and Pressing Module

\begin{tabular}{|c|c|}
\hline Details & Mechanisms \\
\hline $\begin{array}{l}\text { Name: Cooling Structure of Electronic Equipment } \\
\text { Rack (Fan Structured). [23] }\end{array}$ & $\begin{array}{l}\text { The fan unit of each cooling block generates a cooling wind which is passed linearly through the shelf unit from the } \\
\text { bottom to the top of the shelf unit as well as introducing atmosphere through vent holes formed on side face portions } \\
\text { of each fan unit to mix the atmosphere with the cooling wind. The flow rate of the cooling wind will be gradually } \\
\text { increased as the cooling wind proceeds to the upper cooling blocks due to the addition of an upward blowing force } \\
\text { caused by the fans of the fan units. [23] } \\
\text { * Related mechanism for Fan Structured. [24-30] }\end{array}$ \\
\hline $\begin{array}{l}\text { Name : Vacuum cooling technology for the food } \\
\text { processing industry. (Vacuum Cooling). [31] }\end{array}$ & $\begin{array}{l}\text { Vacuum cooling is a batch process whereby moist products containing free water are cooled by evaporation of } \\
\text { moisture under vacuum. Products to be cooled are loaded into a vacuum chamber and the system put into operation. } \\
\text { [31] } \\
\text { * Related mechanism for Vacuum Cooling. [32-37] }\end{array}$ \\
\hline $\begin{array}{l}\text { Name: Device for pressing the coffee powder } \\
\text { within the filter holder (Stamper Presser). [38] }\end{array}$ & $\begin{array}{l}\text { The presser will be pulled down by the lever holder if the powder coffee's cup already been placed under the presser. } \\
\text { [38] } \\
\text { *Related mechanism for Stamper Presser. [39-43] }\end{array}$ \\
\hline Name: Bun machine (Roller Presser). [44] & $\begin{array}{l}\text { The tank will deliver the fermented dough to the roller presser for forming a first layer and then forming a second } \\
\text { layer when it deliver to the second roller presser. [44] } \\
\text { * Related mechanism for Roller Presser. [45-51] }\end{array}$ \\
\hline
\end{tabular}


Table 3. The reviews of Baking Module

\begin{tabular}{|c|c|}
\hline Details & Mechanisms \\
\hline Name: Convection oven (Steam). [52] & $\begin{array}{l}\text { The vapor collection system collects vapor from the cooking chamber during a cooking event, condenses the vapor, } \\
\text { and drains the condensed vapor. The water injection system injects water for impact against a blower wheel for } \\
\text { dispersion into the air circulating through the cooking chamber. The electrical components are housed Within a } \\
\text { housing that in a closed position conceals the components and in a closed position exposes the components for easy } \\
\text { access. The rotational speed and direction of the variable-speed, reversible blower is controlled during a cooking } \\
\text { event according to predetermined speed curves which may include one or more reversal events to achieve more } \\
\text { uniform cooking of food. A main controller is programmable via an operator input (e.g., liquid crystal display touch } \\
\text { screen) to control operating parameters of the oven. [52] } \\
\text { * Related mechanism for Steam. [53-57] }\end{array}$ \\
\hline Name : Conveyor oven (Infrared Heating). [58] & $\begin{array}{l}\text { The oven described herein comprises at least one conveyor for carrying in food products through a bake chamber to } \\
\text { be bake chamber with openings for conveyor(s), an air heating distribution and return System a fan box that contains } \\
\text { means for pressurizing heated air and a drive end that contains the fan motor, conveyor drive motor(s) and oven } \\
\text { temperature controls. [58] } \\
\text { * Related mechanism for Infrared Heating. [59-63] }\end{array}$ \\
\hline Name: Forced convection gas oven (Gas). [64] & $\begin{array}{l}\text { The invention provide a microwave oven having multiple (i.e., at least two or more) independently operable cooking } \\
\text { chambers. Each of the multiple cooking chambers has a separate access door for opening and closing the } \\
\text { corresponding cooking chamber. The microwave oven according to embodiments of the present invention further } \\
\text { includes a control panel for separately controlling the operations of the at least two cooking chambers. [64] } \\
\text { * Related mechanism for Gas. [65-67] }\end{array}$ \\
\hline $\begin{array}{l}\text { Name: Multi access microwave oven (Microwave } \\
\text { Radiation). [68] }\end{array}$ & $\begin{array}{l}\text { The invention provide a microwave oven having multiple (i.e., at least two or more) independently operable cooking } \\
\text { chambers. Each of the multiple cooking chambers has a separate access door for opening and closing the } \\
\text { corresponding cooking chamber. The microwave oven according to embodiments of the present invention further } \\
\text { includes a control panel for separately controlling the operations of the at least two cooking chambers. [68] } \\
\text { * Related mechanism for Microwave Radiation. [69-73] }\end{array}$ \\
\hline $\begin{array}{l}\text { Name: Bidirectional heating cooker (Infrared } \\
\text { Radiation). [74] }\end{array}$ & $\begin{array}{l}\text { Provided is a bidirectional heating cooker that supplements and improves a function of a conventional infrared } \\
\text { radiation cooker, in which the bidirectional heating cooker further includes a lower heating unit that is placed at the } \\
\text { lower end of a cooking pan that is heated by radiant heat irradiated by an infrared lamp and that directly heats the } \\
\text { cooking pan, to thereby heat the cooking pan quickly by the lower heating unit to thus make the upper and lower } \\
\text { portions of food such as none meat put on the cooking pan more quickly roasted than the conventional infrared } \\
\text { radiation cooker and reduce a burden of electric charges based on a shortened heating time of the cooking pan, and to } \\
\text { thereby make it possible to cook food rapidly by an upper heating unit with the infrared lamp and the lower heating } \\
\text { unit that is placed on the cooking pan. [74] } \\
\text { * Related mechanism for Infrared Radiation. [75-78] }\end{array}$ \\
\hline
\end{tabular}

Table 4. Proposed Solution and Improvisation of the chosen patents

\begin{tabular}{|c|c|c|}
\hline Process & Mechanism & Major Improvisation of current patents \\
\hline Depositor & $\begin{array}{l}\text { Name: Method for producing sandwich } \\
\text { cookie having dissimilarly-sized base } \\
\text { cakes (Hopper filler and nozzle) }\end{array}$ & $\begin{array}{l}\text { - The patent must be improvised to meet the requirement for characteristic of Kek } \\
\text { Lapis Sarawak's batter which the batter can be controlled while the batter is } \\
\text { being deposited. }\end{array}$ \\
\hline Baking & Name: Conveyor oven (Infrared Heating) & $\begin{array}{l}\text { - The conveyor oven is being improvised to meet the requirement of Kek Lapis } \\
\text { Sarawak's baking time when the batter is being baked with optimum time. }\end{array}$ \\
\hline Cooling & $\begin{array}{l}\text { Name: Cooling Structure of Electronic } \\
\text { Equipment Rack (Fan Structured) }\end{array}$ & $\begin{array}{l}\text { - The fan structured cooling system is being improvised to meet the requirement } \\
\text { for cooling the cake with optimum time. The main idea is being incorporated in } \\
\text { which a fan is used to cool down the cake. }\end{array}$ \\
\hline Pressing & Name: Bun machine (Roller Presser) & $\begin{array}{l}\text { - The Roller Presser is improvised to meet the requirement for the quality of } \\
\text { layering specification that is being controlled. }\end{array}$ \\
\hline
\end{tabular}




\section{Conclusions}

Prior publications offer greater advantages. For instance, depositor module, showed on how the patent is able to improve the production rate, negative de-aeration effect, depositing by using simple gravity, controllable deformation, technique to prevent uneven flow, minimize waste of material, easy to maintain, improve high speed capabilities as well as delivery of the high viscosity and high withstand and rigidity of the design.

Moreover, the cooling and pressing module have its own advantages whilst reviewing the patents and the journals which are secured specified wind velocity, stable cooling effect, less noise, no mechanical damage, efficient cooling system, low running cost, increased productivity, easy to maintenance, evenly distributing the pressing force, consume less space area and improved the quality of the medium that has been used.

Furthermore, the baking module also has its own advantages while reviewing the patents and the journals which are portability of the design, controllable speed of the device, fast production, controllable heat transfer, improved cooking efficiency and easy to maintenance. Significantly, the improvisation of those ideas is needed to meet up the requirement for development of Kek Lapis Sarawak's machine. Summary of proposed solution and suggestion for improvisation of the chosen patents towards development of Sarawak Kek Lapis's Machine is shown in Table 4.

\section{References}

1. Abidin, A. S. Z., Annisa, J., Tan, W. K., Rigit, A. R. H., Chong, J. S., Kiprawi, M. A., \& Johnapi, P. R. (2014, November). Development of a prototype model for fully automated Sarawak layered cake machine. In Engineering and Technology (BICET 2014), 5th Brunei International Conference on (pp. 15). IET.

2. George. E. D., Linda. C. S., Engineering Design. 5th ed. New York: McGraw-Hill Higher Education, 2012.

3. Abylov, M., \& Durco, J, “Apparatus for depositing a confectionery mass, and method of producing a confectionery product", U.S. Patent 8658 233, Feb 25 2014.

4. Berger, T. G., \& Shtilerman, M, "Dough Feeding System", U.S. Patent 13/098 736, Nov 32011.

5. Campbell, B. V, "Dough Pump and Developer", U.S. Patent 13/007,198, Jul 212011.

6. Bertuzzi, I., Zanetti, U., \& Biondi, A, "FEEDER DEVICE FOR FEEDING A FOOD PRODUCT IN A MACHINE FOR MAKING FILLED PASTA AND MACHINE FOR MAKING FILLED PASTA COMPRISING SUCH A FEEDER DEVICE." U.S. Patent No. 20,150,366,222, Dec 242015.

7. Chiang, W. D, "Forming machine that quickly compacts hollow materials and automatically recycles the materials." U.S. Patent No. 8,057,212, Nov 15 2011.
8. Swami, Shrikant Baslingappa, B. Maiti, and S. K. Das. "Development of an extrusion system for Bori and force characteristics of its batter during extrusion." Journal of food engineering, vol. 73, no. 1, pp. 20-28, March 2006.

9. Gabriele, D., Baldino, N., Migliori, M., De Cindio, B., \& Tricarico, C, "Modelling flow behaviour of dairy foams through a nozzle." Journal of food engineering, vol. 109, no. 2, pp. 218-229, Mar 2012.

10. Kusakari, T., Von Essen, K., \& Hoisington, P. A, "Nozzle layout for fluid droplet ejecting." U.S. Patent No. 8,591,003, Nov 262013.

11. Voegtlin, C, "Method for volume division of dough and implementing device." U.S. Patent Application No. 13/444,468, Sep 202012.

12. Rahaman, M. F., Bari, S., \& Veale, D, "Flow investigation of the product fill valve of filling machine for packaging liquid products." Journal of food engineering, vol. 85, no. 2, pp. 252-258, Mar 2008.

13. Alden, R. M, "High protein whipped collet extrusion crunchy snack product and manufacturing apparatus and process." U.S. Patent Application No. 13/999,015, Aug 72014.

14. Medina, F., Wicker, R., Palmer, J. A., Davis, D. W., Chavez, B. D., \& Gallegos, P. L, "Methods and systems for integrating fluid dispensing technology with stereolithography." U.S. Patent No. 8,252,223, Aug 282012.

15. Thomas, R., Dufort, C., \& Tence, J. F. M. A, "Method and apparatus for manufacturing decorated ice cream confectionery items." U.S. Patent No. 7,658,960, Feb 92010.

16. Villarreal, J. A, "System and method for flavoring food." U.S. Patent No. 9,254,052, Feb 92016.

17. Robinson, C. E., Janulis, T. N., \& Mihalos, M. N, "Ribbon cutter apparatus and method for making sandwich baked goods." U.S. Patent No. 8,334,005, Dec 182012.

18. Groff, E. T., Zaleski Jr, J. S., \& Zvoncheck, K. J, "Rotating nozzle die machine for extrusion of two or more types of dough." U.S. Patent No. 8,177,542, May 152012.

19. Wijshoff, H, "The dynamics of the piezo inkjet printhead operation." Physics reports, vol. 491, no. 4, pp. 77-177, June 2010 .

20. Mihalos, M. N., Janulis, T. N., Robinson, C. E., \& Wines, C, "Method for producing sandwich cookie having dissimilarly-sized base cakes." U.S. Patent No. 8,309,148, Nov 132012.

21. Wang, L., Smith, S., \& Chessari, C, "Continuous-time model predictive control of food extruder." Control Engineering Practice, vol. 16, no. 10, pp. 1173-1183, Oct 2008

22. Rodrigues, D, "High-viscosity dough depositor machine." U.S. Patent No. 8,926,307, Jan 62015.

23. Okuyama, K., Arai, S., Ishiwata, M., \& Takada, H, "Cooling structure of electronic equipment rack." U.S. Patent No. 4,774,631, Sep 271988.

24. Cronin, J. E., Previti-Kelly, R. A., Ryan, J. G., \& Sullivan, T. D, "Cooling microfan arrangements and process." U.S. Patent No. 5,326,430, Jul 51994. 
25. Cronin, J. E., Previti-Kelly, R. A., Ryan, J. G., \& Sullivan, T. D, "Cooling microfan arrangements and process." U.S. Patent No. 5,296,775, Mar 221994

26. Canon, K. H, "Pulse-width modulation speed controllable DC brushless cooling fan." U.S. Patent No. 5,099,181, Mar 241992.

27. Kuo, C. R., Chang, C. Y., \& Wey, T. W, "Axial flow type cooling fan with shrouded blades." U.S. Patent No. 7,192,258, Mar 202007.

28. Hsu, C. C, "Snap coupling cooling fan module." U.S. Patent No. 6,587,342 Jul 12003.

29. Laguerre, O., Duret, S., Hoang, H. M., Guillier, L., \& Flick, D, "Simplified heat transfer modeling in a cold room filled with food products." Journal of Food Engineering, vol. 149, pp. 78-86, Mar 2015.

30. Hoang, H. M., Duret, S., Flick, D., \& Laguerre, O, "Preliminary study of airflow and heat transfer in a cold room filled with apple pallets: Comparison between two modelling approaches and experimental results." Applied Thermal Engineering, vol. 76, pp. 367-381, Feb 2015.

31. McDonald, K., \& Sun, D. W, "Vacuum cooling technology for the food processing industry: a review." Journal of food engineering, vol. 45, no. 2, pp. 55-65, Aug 2000.

32. Anon, "Bakery products cooled in minutes instead of hours. Modulated vacuum cooling is the key." Food Engineering International, vol. 3, pp. 33-34, 1978.

33. Anon, "Vacuum cooling for fruits and vegetables." Food Processing Industry, vol.12, pp. 24, 1981.

34. Anon, "Rapid vacuum cooling." Food Processing Industry, vol. 9, pp. 49, 1981.

35. Mellor, J. D, "Vacuum techniques in the food industry." Food Technology Australia, vol. 32, pp. 77-177, 400-401, 1980.

36. Kratochvil, J., \& Holas, J, "Effect of vacuum cooling on the content of aroma substances and sensory properties of bread." Sobornik UVTIZ Potravinarske Vedy, vol. 2, pp. 241-251, 1984.

37. James, S. J, "Cooling systems for ready meals and cooked products." Process engineering in the food industry, vol. 2, pp. 88-97, 1990.

38. Mazzer, G, "Device for pressing the coffee powder within the filter holder." U.S. Patent No. 20,160,095,463, Apr 72016.

39. Bimman, L, "Clamp for pressing food in pan during cooking." U.S. Patent No. 20,160,095,463, Nov 27 1984.

40. "Bun toasting machine." U.S. Patent No. 20,160,095,463, Dec 171940.

41. Buckley, C, "Adjustable food press." U.S. Patent No. 20,160,095,463, Jan 62015.

42. Errera, R. B, "Food embossing stamper device." U.S. Patent No. 7,331,776, Feb 192008.

43. Kovalevich, P. R., \& Boni, L. M, "Handheld hamburger patty forming system." U.S. Patent No. 8,202,073, Jun 192012.

44. Huang, P. Z, "Bun machine." U.S. Patent No. 20,160,113,291, Apr 282016.

45. Linneman, R. H, "Bun making machine." U.S. Patent No. 2,354,681, May 61947.
46. Emerson, D. B., \& Narwankar, S, "Dough rolling apparatus, method and product." U.S. Patent No. 8,668,485, Mar 112014

47. Kolodesh, M. S., Peters, E. L., \& Madgett, R. J, "Dough rolling apparatus for laminated cookies." U.S. Patent No. 4,511,318, Apr 161985.

48. Quinlan, M. J, "Method and apparatus for producing thin sheets of starch containing food material." U.S. Patent No. 5,268,187, Dec 71993.

49. Hayashi, T, "Method for processing bread dough." U.S. Patent No. 4,276,317, Jun 301981.

50. Hayashi, Torahiko, "Apparatus and method for rolling croissant dough pieces." U.S. Patent No. 4,905,583, Mar 61990.

51. Rhodes, H. C, "Method for distributing moisture in bread dough." U.S. Patent No. 2,479,864, Aug 23 1949.

52. Greenwood, J., \& Reese, R. J, "Convection oven." U.S. Patent No. 8,378,265, Feb 192013.

53. Knost, D, "Baking oven." U.S. Patent No. 5,875,705, Mar 21999.

54. Karabin, T., \& Johnson, L. B, "Chambered flame oven." U.S. Patent No. 8,464,701, Jun 182013.

55. Klobucar, J. M., Pakkala, J. L., \& Yu, G, "Convection combustion oven." U.S. Patent No. 7,905,723, Mar 152011.

56. Baik, O. D., Marcotte, M., \& Castaigne, F, "Cake baking in tunnel type multi-zone industrial ovens Part I. Characterization of baking conditions." Food Research International, vol. 33, no. 7, pp. 587-598, Aug 2000.

57. Baik, O. D., Marcotte, M., \& Castaigne, F, "Cake baking in tunnel type multi-zone industrial ovens Part II. Evaluation of quality parameters." Food Research International, vol. 33, no. 7, pp. 599-607, Aug 2000.

58. Hardenburger, P. A, "Conveyor oven." U.S. Patent No. 6,526,961, Mar 42003.

59. Shukla, K. C., Hurley, J. R., Orcheski, C. J., \& Grimanis, M. P, "Conveyor oven." U.S. Patent No. 4,951,648, Aug 281990.

60. Smith, S. R, "Conveyorized baking oven with steam tunnel." U.S. Patent No. 8,881,646, Nov 112014.

61. Alden, L. B, "Infra-red baking oven." U.S. Patent No. 4,960,977, Oct 21990.

62. Lee, J. H, "Infrared radiation cooker." U.S. Patent No. 8,948,579, Feb 32015.

63. Westerberg, E. R., \& Robert, I. B. I, "Visible light and infra-red cooking apparatus." U.S. Patent No. 5,517,005, May 141996.

64. Violi, R, "Forced convection gas oven." U.S. Patent No. 7,100,596, Sep 52006.

65. Onuschak, A. D, "Dual mode convection oven." U.S. Patent No. 6,116,895, Sep 122000.

66. Hwang, Y. I, "Overheated steam oven." U.S. Patent No. 7,143,761, Dec 52006.

67. Bonuso, J. L., \& Swayne, S. M, "Priority controlled multi-fan convection oven." U.S. Patent No. 8,304,695, Nov 62012.

68. Blazevich, J. Z." U.S. Patent Application No. 12/365,137, Aug 52010. 
69. Dobie, M. J., Norris, J. R., Cooper, N. S., Bacigalupe, C., \& Foreman, R. W, "Multi-shelved convection microwave oven." U.S. Patent No. 7,087,872. Aug 82006.

70. Fang, L, "Microwave oven with rotary cooking apparatus." U.S. Patent No. 8,847,131, Sep 302014.

71. Lee, S. G, "Built-in microwave oven." U.S. Patent No. 6,528,774, Mar 42003.

72. Keskin, S. O., Sumnu, G., \& Sahin, S, "Bread baking in halogen lamp-microwave combination oven." Food Research International, vol. 37, no. 5, pp. 489-495, Jun 2004.

73. Megahey, E. K., McMinn, W. A. M., \& Magee, T. R. A, "Experimental study of microwave baking of Madeira cake batter." Food and Bioproducts Processing, vol. 83, no. 4, pp. 277-287, Dec 2005.

74. Lee, J. H, "Bidirectional heating cooker." U.S. Patent No. 8,761,588, Jun 242014.

75. Moreth, R. E, "High efficiency carousel infrared oven." U.S. Patent No. 6,250,210, Jun 262001.

76. Jovanovic, D, "Infrared apparatus for baking pastries and pizzas." U.S. Patent No. 5,378,872, Jan 31995.

77. Ploteau, J. P., Glouannec, P., Nicolas, V., \& Magueresse, A, "Experimental investigation of French bread baking under conventional conditions or short infrared emitters." Applied Thermal Engineering, vol. 75, pp. 461-467, Jan 2015.

78. Sumnu, G., Sahin, S., \& Sevimli, M, "Microwave, infrared and infrared-microwave combination baking of cakes." Journal of food engineering, vol. 71, no. 2, pp. 150-155, Nov 2005. 